\title{
Compared to what? Estimating the relative concentration of crime at places using systematic and other reviews
}

\author{
John E. Eck ${ }^{1 *}$, YongJei Lee², SooHyun $\mathrm{O}^{1}$ and Natalie Martinez ${ }^{1}$
}

\begin{abstract}
Background: That crime is concentrated at a few places is well established by over 44 studies. This is true whether one examines addresses or street segments. Additionally, crime is concentrated among offenders and victims. Many physical, biological, and social phenomena are concentrated as well. This raises a question: is crime more or less concentrated at places than other phenomena? If it is not, then crime concentration maybe the result of standard ubiquitous processes that operate in nature. If crime is more or is less concentrated than other phenomena, then researchers need to ask why.

Methods: We synthesize results from three systematic reviews and review other literatures to provide preliminary answers.

Results: We find that although crime is more concentrated at addresses than other spatial units, this is due to the fact that more addresses have no crime than is true of larger units. When only places with one or more crimes are examined, place crime is no more concentrated than other spatial unit crime. Crime appears to be concentrated at places at about the same level as it is concentrated among offenders or victims. And crime concentration does not appear to be peculiarly concentrated compared to non-crime related phenomena.
\end{abstract}

Conclusions: The concentration of crime at places is unexceptional, and should be treated as one manifestation of a general tendency of things to be concentrated.

\section{Background}

That crime is concentrated at a few places is well established by over 44 studies (Lee et al. 2017). This has major implications for how we develop and test crime theories and how we deliver prevention and enforcement services (Weisburd et al. 2016). What was at first an exciting and novel finding in the late 1980s (Pierce et al. 1988; Sherman et al. 1989) has now become accepted fact. Weisburd calls the regularity of crime concentration at street segments "The Law of Crime Concentration" (Weisburd 2015) while Wilcox and Eck term the concentration of crime at addresses "The Iron Law of Crime Concentration" (Wilcox and Eck 2011).

*Correspondence: John.eck@uc.edu

1 School of Criminal Justice, University of Cincinnati, Cincinnati, Ohio, USA Full list of author information is available at the end of the article
The term "place" has a number of meanings in the crime literature (Madensen and Eck 2013) so we need to specify how we use the term in this paper. Unless we say otherwise, places are either addresses (usually real-estate parcels including buildings) or street segments (usually a portion of a street, from one intersection to the next, including parcels along either side). These correspond to proprietary and proximal places, as defined by Madensen and Eck (2013).

In addition to places, crime is concentrated along numerous dimensions, some spatial and others not spatial. Some of the earliest modern criminological research highlighted the concentration of offenders in neighborhoods (Shaw and McKay 1942). We have known for many years that crime is concentrated among victims (Farrell et al. 1995). And we have known for longer that crime is concentrated among offenders (Wolfgang et al. 1972). 
Within police organizations, both useful and detrimental behaviors are concentrated among officers. Forst et al. (1982) documented that a small proportion of all police officers in Washington, DC were responsible for most of the arrests resulting in the convictions of offenders. More recently, the Chicago Tribune showed that the behavior of about $1 \%$ of the Chicago Police's officers were responsible for almost a third of the misconduct lawsuits settled in a 6-year period ending in 2015 (Caputo and Gorner 2016).

Just as important, many social phenomena are concentrated: wealth and income are concentrated among a small proportion of individuals and households (Lorenz 1905; Piketty and Saez 2003); the market share among firms is highly concentrated, so that in most markets a few firms dominate (Rhoades 1993); a small proportion of the firms employ a large fraction of the workforce (Ijiri and Simon 2013); a few individuals consume most of the emergency medical services expenditures (Jacobi 2012); a small proportion of individuals have a large proportion of the accidental injuries (Visser et al. 2007); and a small fraction of words are used frequently, but most words are seldom used (Zipf 1949). ${ }^{1}$

Most cities are small, but a small proportion of all cities contain the majority of people who live in cities (Gabaix 1999). A third of the carbon emitted by power plants in the U.S. comes from $1 \%$ of those plants (Schneider, Madsen, and Boggs 2013). Visits and views of websites are concentrated in a relatively few sites (Schmeiser 2015). A few participants on Twitter are responsible for much of the misogyny expressed (Bartlett et al. 2014). Most fatal conflicts have few fatalities, but a few conflicts have an extremely large number of casualties (Richardson 1948). The same is true of terrorist attacks (Clauset et al. 2007). It is true about civilian firearm ownership: about $5 \%$ of the gun owners in the United States possess $50 \%$ of the civilian guns in that country (Beckett 2016). And it is true of journal citations: most are not cited, but a very few are cited a great many times (Noorden et al. 2014).

Biological phenomena often are highly concentrated too (Gisiger 2001). Here are three examples. McElligott and Hayden (2000) show in a study of an Irish deer herd, that $3 \%$ of male fallow deer had $73 \%$ of all successful matings. Most little brown ants do little or no work for their colony, but a few do most of the work (Charbonneau and Dornhaus 2015). Half of the carbon storage in the

\footnotetext{
${ }^{1}$ In a further illustration of the ubiquity of concentration, consider this paper. Once written, we discovered that we cited 55 documents containing a total of 228 authors (authors in multiple documents are counted multiple times). The number of authors for each document varies from one to 98 . Less than $4 \%$ of the referenced documents ( 2 studies) contribute about 51\% of the authors.
}

Amazonian jungle is due to $1 \%$ of the tree species (Fauset et al. 2015).

Concentration is common among physical phenomena. The total energy released by earthquakes is concentrated among a small fraction of all earthquakes (Richter 1935). Most avalanches are small, but a few are massive, and the same is true of volcanic eruptions and solar flares (Bak 1994). Most cosmic dust particles are tiny, but a small proportion of these particles contain a large portion of the mater found in such grains (Mathis et al. 1977). Laherrère and Sornette (1998) describe the general property of concentration in nature, and give as examples the radio and light intensity of galaxies (a small proportion of galaxies emit a large proportion of the radio and light observed) and oil field size in the Gulf of Mexico (most fields are small, but a relatively few fields have much of the oil).

With so many phenomena, across so many fields of research, showing concentration, ${ }^{2}$ perhaps rather than ask, how concentrated is crime at places, we should ask, how concentrated is crime at places compared to other phenomena? Is it more concentrated? Is it less concentrated? Or is it about the same level of concentration as most other phenomena? If crime is about as concentrated at places as other phenomena are concentrated, then the explanation for crime concentration will require us to look at explanations for concentration in general. If crime is more or less concentrated than other phenomena, then the explanation involves looking for something special about places and crime.

Though others have remarked upon how crime-place concentration is similar to other phenomena (Farrell 2015; Sherman 2007; Weisburd 2015), this paper is the first to systematically compare the concentration of crime at places to other forms of crime concentration and concentration of other phenomena unrelated to crime. Because the concentration of crime at places has been systematically examined by Lee et al. (2017), we do not review this literature further. Rather we use systematic and other literature reviews to make a series of comparisons.

This paper is organized like a sandwich. At the center is a comparison of three systematic reviews. We begin with the top slice of bread: a comparison of the concentration

\footnotetext{
2 Though concentration is extremely common in natural and human affairs (Laherrère and Sornette 1998; Schroeder 1991), it is difficult to determine if concentration is more common than non-concentration. Outside the distribution of measurement error, it would appear that we should always bet that a phenomenon is concentrated until we have evidence against it. Nevertheless, we are unaware of a scientific study that could support this heuristic. It is clear, however, that concentration is so common that we should expect it more than we do.
} 
of crime at addresses to its concentration at street segments and across neighborhoods. There is not a large literature to examine here, but that literature shows crime to be more concentrated the smaller the spatial unit. We supplement this literature with an analysis of concentration across four geographic scales in Cincinnati.

We then turn to comparing place concentration to concentration of crime among victims and offenders. This is the core of our study. Well over a quarter of a century ago, Spelman and Eck (1989) compared the relative concentration of crime along these three critical dimensions of crime. They found crime more concentrated at places than among offenders or victims. Given the passage of time and accumulation of many more studies, it is important to check whether their findings are valid. We make use of three systematic reviews to compare findings from three sizable bodies of literature. We also look at evidence about place concentration found in some repeat victimization studies. Within the limits of the way data on place, offender, and victim concentration has been measured, we find that there is little evidence to suggest that crime is substantially more concentrated at places than among victims or offenders.

In the fourth section of this paper, the bottom slice of bread, we compare crime-place concentration to concentration in other phenomena. This is such a large and diverse area that a systematic review is extremely difficult. So instead, we draw on Newman's (2005) review of concentration because he examines a broad array of phenomena in a systematic manner. It appears that crime concentration is not exceptional, whether it is concentration among places, offenders, or victims.

In the final section of this paper, we draw out implications from these comparisons that might be useful to researchers and policy makers. An important implication is that concentration of crime is greater among places than among neighborhoods, suggesting that theory and policy should focus on places. Another implication is that the concentration of crime at places is not substantially different that the concentration of crime among possible victims or possible offenders. But give that so many phenomena in human behavior, and in nature overall, are concentrated, place-crime concentration appears ordinary. Thus, in the absence of data, whether for policy or for theory, we should default to an assumption of concentration until valid data suggests otherwise.

\section{Compared to other spatial units}

The most obvious comparison of crime concentration at places is to crime concentration at other spatial aggregations. The relative concentration of crime at places, compared to other geographic units, matters for three reasons. First, if crime is equally concentrated among places and neighborhoods, then this has important implications for theory. It implies that the geographic scale of analysis is irrelevant. Stated another way, crime is geographically scale invariant.

Whether or not crime is geographically scale invariant is important as this points to classes of explanations that may be valid and suggests other classes of explanations that are likely to be misleading. Gisiger (2001) gives this example of scale invariance on a geographic scale.

"It is a well-established fact that a photograph of a geological feature, such as a rock or a landscape, is useless if it does not include an object that defines the scale: a coin, a person, trees, buildings, etc. This fact, which has been known to geologists long before it came to interest researchers from other fields, is described as scale invariance: a geological feature stays roughly the same as we look at it at larger or smaller scales. In other words, there are no patterns there that the eye can identify as having a typical size. The same patterns roughly repeat themselves on a whole range of scales." (p. 164).

If a phenomenon is scale invariant, then there is likely to be a singular process that gives rise to its manifestations across a range of scales (Bak 1996; Gisiger 2001; Schroeder 1991). If crime is geographically scale-free then we should see the same degree of crime concentration regardless of the geographic scale used. If we see this, this implies that the same process that creates crime clusters at addresses drives the creation of clusters of crime at the segment and neighborhood levels. If crime is not scale invariant, this implies that there are different processes at each level, or that there is some form of hierarchical arrangement where higher level contexts help shape the outcomes of lower level processes (e.g., street segments provide a context that moderates the address level dynamics of crime).

Second, if crime is more concentrated as one examines smaller units, this implies that one should build explanations from the bottom up. The value of the larger units is that they can provide contexts for processes occurring in smaller units (Wilcox et al. 2002). In contrast, if crime in neighborhoods are more concentrated than crime at places, then the opposite is true. We would want to build our theories at the neighborhood level, and use places as moderators of neighborhood influences.

Finally, the relative concentration matters for policy. Assuming resources are scarce, they need to be carefully allocated to where they produce the most benefits. Therefore, resources should be applied where crime is most concentrated: on the worst places or neighborhoods. Equal concentration between neighborhoods and places suggests that targeting either the most 
crime-ridden neighborhoods or places would be equally useful. If places have more concentration, policy makers should focus on these units rather than neighborhoods. And if neighborhoods have the most concentration, then this unit should be the policy focus.

There has been a modest amount of research on the relative concentration of crime across different spatial units. It consistently shows that smaller spatial areas are more concentrated than larger ones. Andresen and Malleson (2010) examine the stability of crime concentration at the street segment level over time in Vancouver, British Columbia. They show that crime concentration is more stable at this level than at a larger area level. This is true when they examine all segments and areas, and when they examine only those segments and areas with crime (eliminating segments and areas that have no crime). Johnson (2010) compared burglary concentration at the street segment level to the same 12,806 burglaries grouped by census areas for a U.K. county. He found that crime is more concentrated at the segment level. Recently, Steenbeek and Weisburd (2016) reported very similar results for The Hague, in the Netherlands.

To contribute to the filling of this gap in our comparisons, we measured concentration in Cincinnati in four ways. First, we looked at Cincinnati's 71 neighborhoods. ${ }^{3}$ These average about 1.52 square miles (about $6500 \mathrm{ft}$. by $6500 \mathrm{ft}$.) but vary a great deal around this mean, which makes it possible that any crime concentration might be largely due to the land area. To control for neighborhood size, and to observe concentration in smaller areas, we also created a grid of $2500 \mathrm{ft}$. by $2500 \mathrm{ft}$. cells (about .224 square miles each $)^{4}$ and counted crimes within each cell. We then measured crime concentration across these synthetic neighborhoods. Next, we measured crime concentration for Cincinnati's 13,550 street segments, using procedures similar to Weisburd et al. (2004). That is, we defined a segment as a street from intersection to intersection, and counted the crimes that occurred at all addresses along both sides of this street portion.

\footnotetext{
${ }^{3}$ Although the city recognizes 52 neighborhoods in most databases, it also recognizes a number of subneighborhoods or larger areas. This provides 71 neighborhood areas and reduces the disparity in neighborhood size, somewhat.

${ }^{4}$ The 2500 feet by 2500 feet grid cell approximates the size of the average block-group in Cincinnati. In 2010, according to the U.S. Census Bureau, 39 blocks comprise a single block-group, on average. We imagined a grid of cells, each of which is about six blocks on each side. Because the average length of the side of each block is about 500 feet, the average size of a blockgroup is 3000 feet by 3000 feet. However, as mean values are always inflated by a few outliers, we chose to use five blocks per side rather than six blocks to represent the size of block-groups. This yielded the 2500 feet by 2500 feet cells.
}

However, we also included the crimes at intersections (i.e., addresses at intersections). ${ }^{5}$ Finally, we measured crime concentration at the address level, with the address being taken from police reports. There were 115,769 addresses in Cincinnati. If a police report stated that a crime occurred at a particular address, then we assigned it to that address.

We measured crime concentration in two ways. First, we plotted Lorenz curves for the two areas, segments, and addresses. Second, we calculated the Gini Coefficient for each geographic unit. Gini coefficient is a common measure of concentration that varies from 0 to 1 . In this analysis, a zero would indicate a perfectly even spread of crime across the units (no concentration), and a one would indicate that all crime is located in a single unit (perfect concentration). The results are shown in Fig. 1.

Here we see four Lorenz curves, and a reference line. The horizontal axis shows the cumulative percentage of the units (neighborhoods, segments or addresses) arranged from those units with the least crime to the units with the most crime. Thus, zero percent of the units are at the far left and 100\% of the units are at the far right. The vertical axis shows the cumulative percentage of crimes at the relevant units. This axis also spans the interval zero to $100 \%$. If crime were equally spread across the city, then the Lorenz curve would follow the diagonal line. This is a reference line signifying equality, and is purely theoretical.

The more bowed away from the line of equality, the greater the concentration. All four curves are bowed downward and away from the line of equality, indicating some degree of concentration. As we move from left to right, the curves bend upward, and at the far right, they can bend up steeply. This is because the most crimeinvolved units are contributing a disproportionate share of crime. It is clear that the smaller a unit's area, the more it deviates from the line of equality. Areas have less crime concentration than addresses, and segments fall in between.

The Gini Coefficients give numerical summaries of the visual display seen in the graphs. This coefficient is the ratio between two numbers: the area on the chart located between the line of equality and the relevant Lorenz curve, and the area between the relevant Lorenz curve and the lower and right perimeters of the chart. Think of the Lorenz curve as being produced by connecting the tips of a series of 100 bars ( $1 \%$ of the places for each)

\footnotetext{
${ }^{5}$ We have worked with the Cincinnati Police on a number of projects over many years and have found that they are diligent about coding crimes to precise locations and seldom attribute crimes to intersections when they occur within a block.
} 


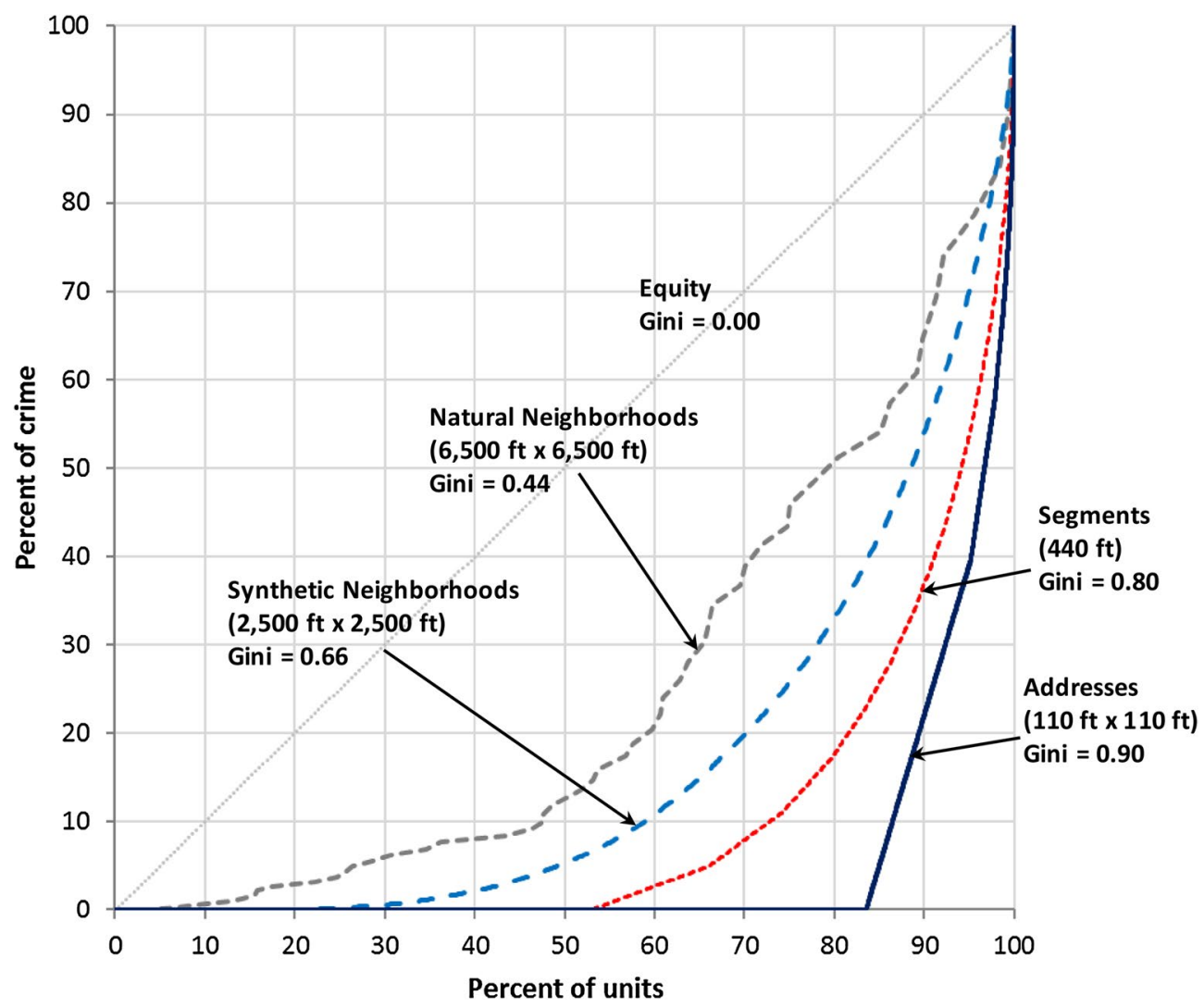

Fig. 1 Lorenz curves for Cincinnati

whose height is determined by the number of crimes. Summing the number of crimes in each bar gives the area under the Lorenz curve. The area under the line of equality is half the volume of the chart, so subtracting the area under the Lorenz curve from this number provides an estimate of the area between the line of equality and the Lorenz curve. Using this information, we can calculate the Gini coefficient.

This is a single study, but it is probably highly generalizable because of the mathematics of concentration. Most of the increase in concentration is due to the increasing number of spatial units with zero crimes as one shifts from examining larger to examining smaller units. Crime is a rare occurrence so most of the segments and addresses will have no crime. Neighborhoods, on the other hand, contain a heterogeneous set of mostly nocrime places, and some crime places. There will be few or no neighborhoods without at least a few crime places. As the neighborhood area size increases, the chance of finding a neighborhood without crime diminishes to zero. Compare the two extremes in Fig. 1. The Lorenz curve for natural neighborhoods departs from the horizontal axis early, moving from left to right. The Lorenz curve for addresses clings to the horizontal axis to around
$83 \%$, because about $83 \%$ of the addresses have no crime, whereas all neighborhoods have at least a small fraction of the city's crime. As long as crime is improbable for the average address, and somewhat dispersed across a jurisdiction, large areas will always have less concentration than tiny areas. In short, this finding is the result of averaging across units that are subject to low probability events.

It is apparent that compared to neighborhoods, crime is far more concentrated at places (whether measured by segments or addresses). Further, the smaller the place the greater the concentration. Though we do not have data to test this conjecture, if we had data describing areas within buildings, it is likely that crime would be even more highly concentrated still. Rengert et al. (2001) show that in a high-rise university office building crime is concentrated near the elevators on all floors. Unfortunately, there is insufficient data to indicate whether this within-address concentration is greater than address concentration. It is likely that in most large apartment buildings with some crime, most rental units would little or no crime, but a few would have most of the crime in the building. It also sounds plausible that in a large retail store, theft is likely to be more common in some areas 
than in others. Even within a single, free standing home, if there are multiple crime events, it may be that there are a few rooms where these events are more common (e.g., a bedroom or kitchen) than in the typical room (e.g., basement, laundry, bathroom, or child's room). It might be some time before police collect crime data at this level of precision. However, if a police agency routinely and accurately records apartment numbers then this conjecture can be tested with their data.

These findings suggest three conclusions. First, because crime is not equally concentrated at different spatial units, this implies that scale matters. Thus, it seems unlikely there is a single explanation for crime concentration the covers all scales. Second, the results imply we should build explanations from the smallest unitsaddress-level places-upward rather than start with neighborhoods. It is likely that each successively larger area provides a context for processes within smaller units, but understanding the most micro-level processes is fundamental for understanding crime processes in larger area. Third, policy development should follow the same tactic: begin with policies at the address level and then modify them to fit neighborhood contexts.

We can also compare concentration across spatial units when we look only at crime-involved units. That is, we only use neighborhoods and places with one or more crimes when we draw the Lorenz curves and calculate the Gini coefficients. ${ }^{6}$ These results are shown in Fig. 2 and in Table 1.

Our results are substantially different from what we discovered when looking at all units, regardless of crime involvement. When examining only units with crime (eliminating neighborhoods and places with no crime), four things change. First, the Gini coefficients decline substantially, except for neighborhoods. This exception is easily accounted for: all neighborhoods have at least one crime, so no neighborhood is excluded. Second, the difference between the largest and smallest Gini is half that of the difference when all units are examined. When all units are examined the difference between the largest and smallest Gini is .46. When uninvolved units are eliminated, the difference is .23. Third, the ordering of the Gini coefficients appears arbitrary, rather than systematic. In Fig. 1 we saw a logical ordering: as the geographic

\footnotetext{
${ }^{6}$ The Gini coefficients used here are based on the theoretical line of equality. As one perceptive reviewer noted, it is possible to use an empirically derived reference line using a Monte Carlo simulation. Any Gini coefficient based on such a reference line cannot be greater than Gini coefficients based on the theoretical line, and are very likely to be smaller. It is unclear, however, whether using an empirical reference line would produce substantively different findings. Though very interesting, the empirical reference comparison is beyond the scope of this paper, Therefore, we encourage others to pursue this line of enquiry.
}

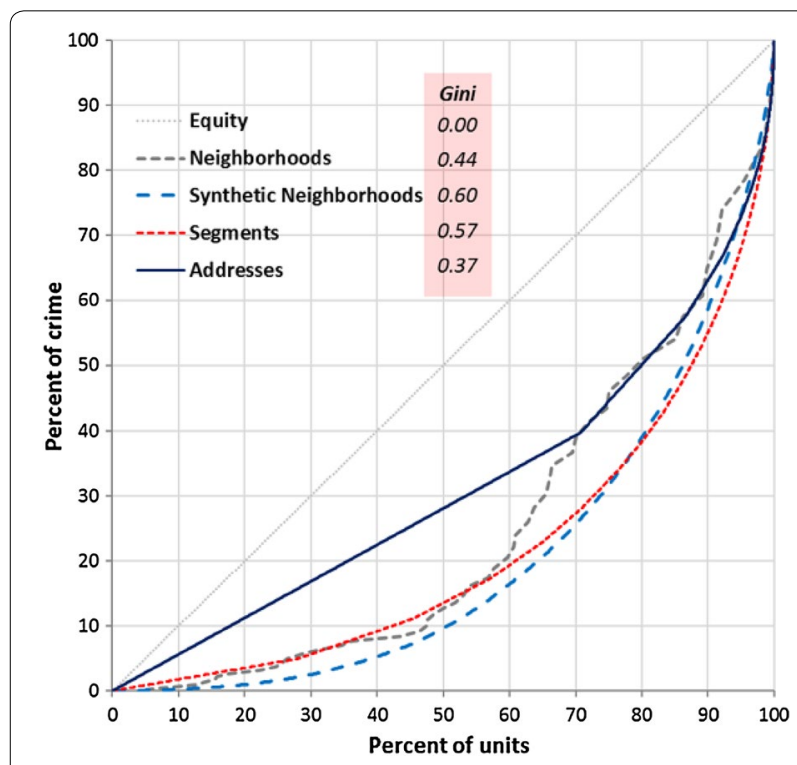

Fig. 2 Lorenz curves excluding uninvolved units

unit shrank, the Gini rose. In Fig. 2, the smallest Gini is for addresses, then natural neighborhoods, then segments, and then artificial neighborhood grid cell. Finally, if we look at the percentage of crime in the most crimeafflicted units (the top 10\%), we see that this drops and the differences among the units is a paltry $7 \%$ (compared to $42 \%$ when uninvolved units are included).

It seems that the principle reason for the smaller Gini coefficient for addresses is due to the fact that crime is rare at the address level, so the least-involved places have a single crime. Thus, the left of the Lorenz curve is stiff and inflexible. With larger units, in contrast, a space can have one, two, three, or more crimes and still be among the least involved. This allows their Lorenz curves to flex. If we had used 10 years of data, it is highly likely that this would allow the address Lorenz curve to flex more, and look like the other Lorenz curves.

This combination of findings suggests that for theory and practice, we cannot distinguish among these units with regard to the concentration of crime, when only crime-involved units are examined. If the ordering of the Gini coefficients were systematic-larger units had larger values than smaller ones, or vice versa-then we might draw a different conclusion. But the arbitrariness of the ordering, combined with the similarity among the coefficients, suggests that crime concentration is similar across geographic scales.

This suggests different implications than we drew from looking at all units (involved and uninvolved). First, because crime is equally concentrated at different spatial units, this implies that scale does not matter: that 
Table 1 Consequences of eliminating uninvolved units

\begin{tabular}{llllll}
\hline & \multicolumn{2}{l}{ Gini coefficients } & & \multicolumn{2}{l}{ Proportion of crime in the most Involved 10\% } \\
\cline { 5 - 6 } & Including uninvolved units & Excluding uninvolved units & & Including uninvolved units & Excluding uninvolved units \\
\hline Address & .90 & .37 & .80 & .38 \\
Segment & .80 & .57 & .63 & .45 & .45 \\
Grid cell & .66 & .44 & .38 & .40 \\
Neighborhood & .44 & .23 & .42 & .38 \\
Maximum-minimum & .46 & &
\end{tabular}

there is a single explanation for crime concentration, given involvement, that covers all scales. This leads to the second implication. Given that crime is hyperlocalthe offender and target must be in very close proximity to each other for almost all common crimes-address level mechanisms are likely to drive crime regardless of the unit examined. We should build explanations from the smallest units-address-level places-and can largely ignore larger spatial units when we seek to understand repeated crime. Third, if there are few or no contextual effects, then the same policies to address concentrated crime would work regardless of the neighborhood in which they are applied.

Together, these two sets of conclusions bolster a point made by Clarke and Cornish (2000) and by Farrell et al. (1995): theories and policies should distinguish between explaining and preventing initial crime involvement, and explaining or preventing subsequent crimes given involvement. The first set of theories and policies are clearly not scale invariant so context does matter. The second set of theories and policies maybe scale invariant so context matters much less or not at all. Common to both sets of implications is the idea that one should start with the smallest units when developing either theory or policy.

\section{Compared to other routine activity theory elements}

If crime is more concentrated at the smallest measurable geographical units than at larger spatial units, how does place concentration compare to other micro-level units? Routine activity theory (Cohen and Felson 1979) describes crime as the interaction of three basic entities: places, offenders, and victims (Felson 1995). Thus, comparing place concentration to concentration of crime among offenders and victims is important.

One would expect that place, offender, and victim involvement in crime would be roughly equally concentrated, given that all three are required for crimes. However, one can imagine there being substantial differences in concentration. Offenders might be highly concentrated, for example, but the active offenders might attack a wide variety of victims at many different places. Or, in another example, a few victims have numerous crime experiences at the hands of many different offenders at different places. Or, in the final example, a few places have much crime but these are perpetrated my different offenders against different victims. In each of these scenarios concentration is unequal among places, offenders, and victims. Knowing something about their relative concentration tells us something important about which of these possibilities is most likely.

The relative concentration across places, offenders, and victims has policy implications, too. Everything else being equal, a sound crime prevention policy would focus on the element that is most concentrated. If concentration is equal, then policies that simultaneously address places, offenders, and victims make more sense.

Three systematic reviews of the place, offender, and victim concentration literature make such a comparison possible. In this section we make three types of comparisons. First we look at distributions that include places and people who are not involved in crime, as well as places and people who have single or multiple encounters with crime. Second, we look at only places, offenders, and victims who have one or more encounters. Finally, we compare two ways of measuring place concentration: from victimization survey data where the crimes are likely to be place-based and from police data that is routinely used in place research. We conclude that there are not large differences in crime concentration among places, offenders, and victims and there are not large differences in crime concentration at places due to measurement differences.

\section{Places, offenders, and victims}

The POV project at the University of Cincinnati set out to synthesize the evidence of crime concentration for places, offenders and victims and to estimate the crime concentration for all three phenomena. In three papers published in this issue (Lee et al. 2017; Martinez et al. 2017), the authors applied a common set of methods to 


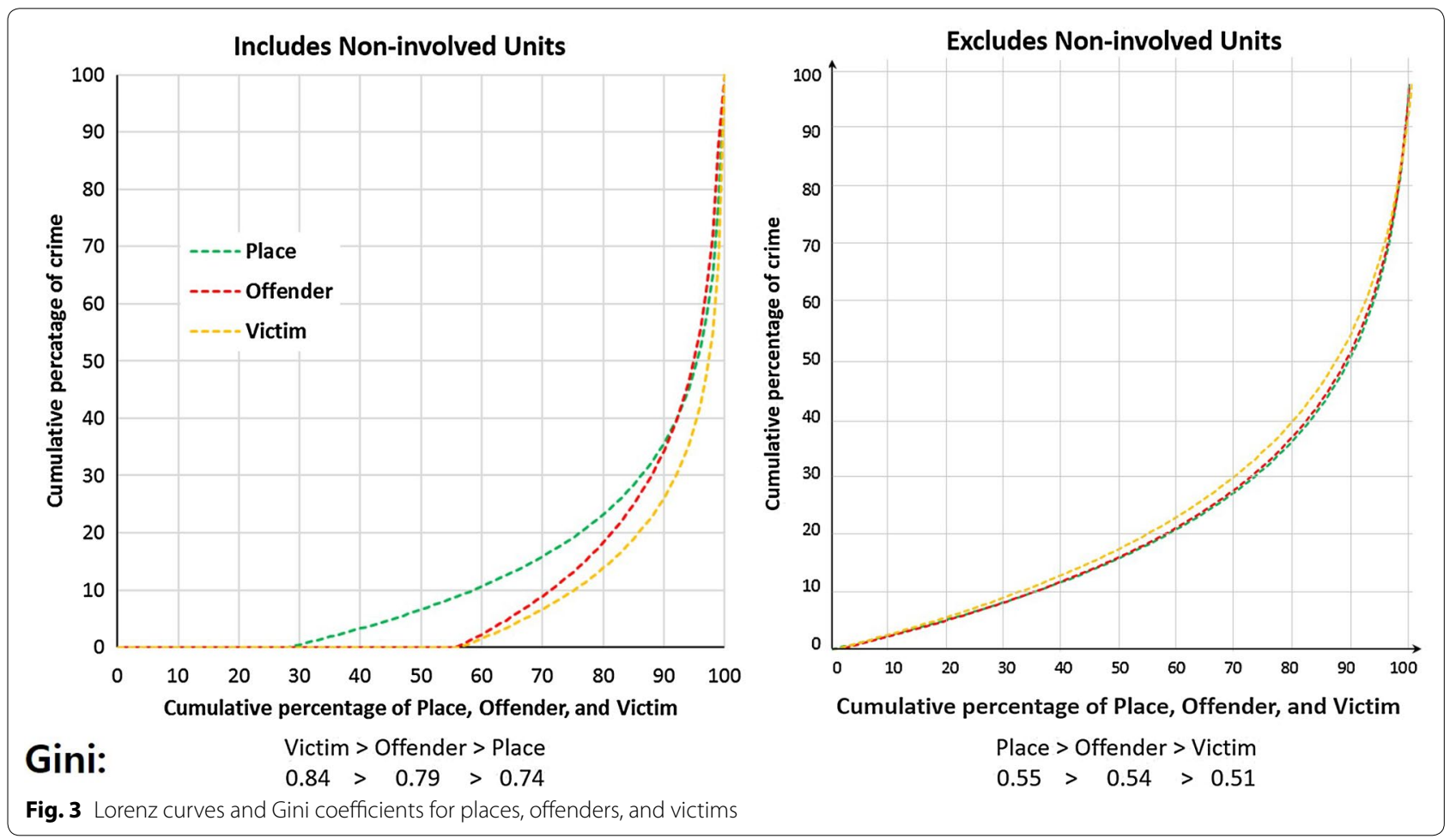

locate research showing the distribution of crime among places, offenders, and victims published since the 1970s (and before in the case for offenders). Because the three reviews used a standard set of analytical methods, comparisons among the three sets of findings control for the methods used in the three reviews. That is, any errors in synthesizing the findings across studies will be common to all three domains, so these errors cannot be the source of differences between the three domains.

We can compare crime concentration at places to crime concentration among offenders and victims, with and without non-involved cases. ${ }^{7}$ We show this in Fig. 3. In the left panel of this figure we see three relatively distinct Lorenz curves.

When we examine studies including crime uninvolved places and people (left panel), the Gini coefficients for crime at places, offenders and victims are rather high. Given that these estimates come from averaging heterogeneous studies, we should exercise some caution

\footnotetext{
${ }^{7}$ Although places without crime are easy to understand, it is peculiar that we refer to offenders or victims who did not commit a crime or who were not victims. The status as an offender or a victim originates with involvement. Nevertheless, we have numerous studies of population samples. Each study contains a large proportion of people who had no crime involvement, and a smaller proportion of who were offenders or victims, during a study's time window. For simplicity of discussion, we will refer to such studies as offender or victim studies, and refer to crime uninvolved members of these study samples as uninvolved offenders or uninvolved victims.
}

in interpreting the rank order of the Gini coefficients. The place studies, for example, include both street segments and addresses, as well as studies of small (subneighborhood) units that are neither street segments nor addresses. The offender studies include findings from official reports on males and females, as well as juveniles and adults. The victim studies include both residential and commercial crimes, for example. It appears that crime is more concentrated among possible victims than possible offenders and that crime is least concentrated at places, but as we will note shortly, these differences maybe more apparent than real (Table 2).

When we look only at crime-involved places, offenders, and victims, we find these apparent differences almost completely disappear (right panel). The Gini coefficients are smaller and virtually the same. The smaller Gini coefficients suggest that much of the concentration we see in the left panel is due to the fact that a large proportion of the places or people are not involved in crime. Nonetheless, even when only crime-involved places and people are examined, crime is still substantially concentrated. The similarity of the Gini coefficients in the right panel of Fig. 3 suggests that the process of repeated crime involvement (once involved) may be similar across places, offenders, and victims, as noted by Farrell (2015) and Eck (2001).

Figure 4 shows the fit between the data points from the studies reviewed and the estimated logarithmic functions 
Table 2 Summary of POV crime concentration findings. Sources: places, Lee et al. (2017); offenders, Martinez et al. (2017); and victims, $O$ et al. (2017)

\begin{tabular}{|c|c|c|c|c|c|}
\hline \multirow{2}{*}{$\begin{array}{l}\text { Reviews (years of studies } \\
\text { examined) }\end{array}$} & \multirow[t]{2}{*}{ Studies $^{\mathrm{a}}$} & \multirow[t]{2}{*}{ Findings $^{a}$} & \multirow{2}{*}{$\begin{array}{l}\text { Average proportion of cases } \\
\text { without crime (\%) }\end{array}$} & \multicolumn{2}{|c|}{ Average proportion of crime for worst $10 \%$ of cases } \\
\hline & & & & $\begin{array}{l}\text { Including cases with- } \\
\text { out crimes (\%) }\end{array}$ & $\begin{array}{l}\text { Excluding cases } \\
\text { without crimes (\%) }\end{array}$ \\
\hline Places (1978-2015) & $26 / 19$ & $428 / 310$ & 73.6 & 64.2 & 42.4 \\
\hline Offenders (1950-2014) & $15 / 27$ & $154 / 288$ & 73.0 & 65.6 & 41.3 \\
\hline Victims (1977-2014) & $20 / 20$ & $397 / 359$ & 82.9 & 73.8 & 34.8 \\
\hline
\end{tabular}

a First figure indicates the number of studies or finding where both crime-involved cases and uninvolved cases were examined. The second number of studies or findings where only the crime-involved cases were examined
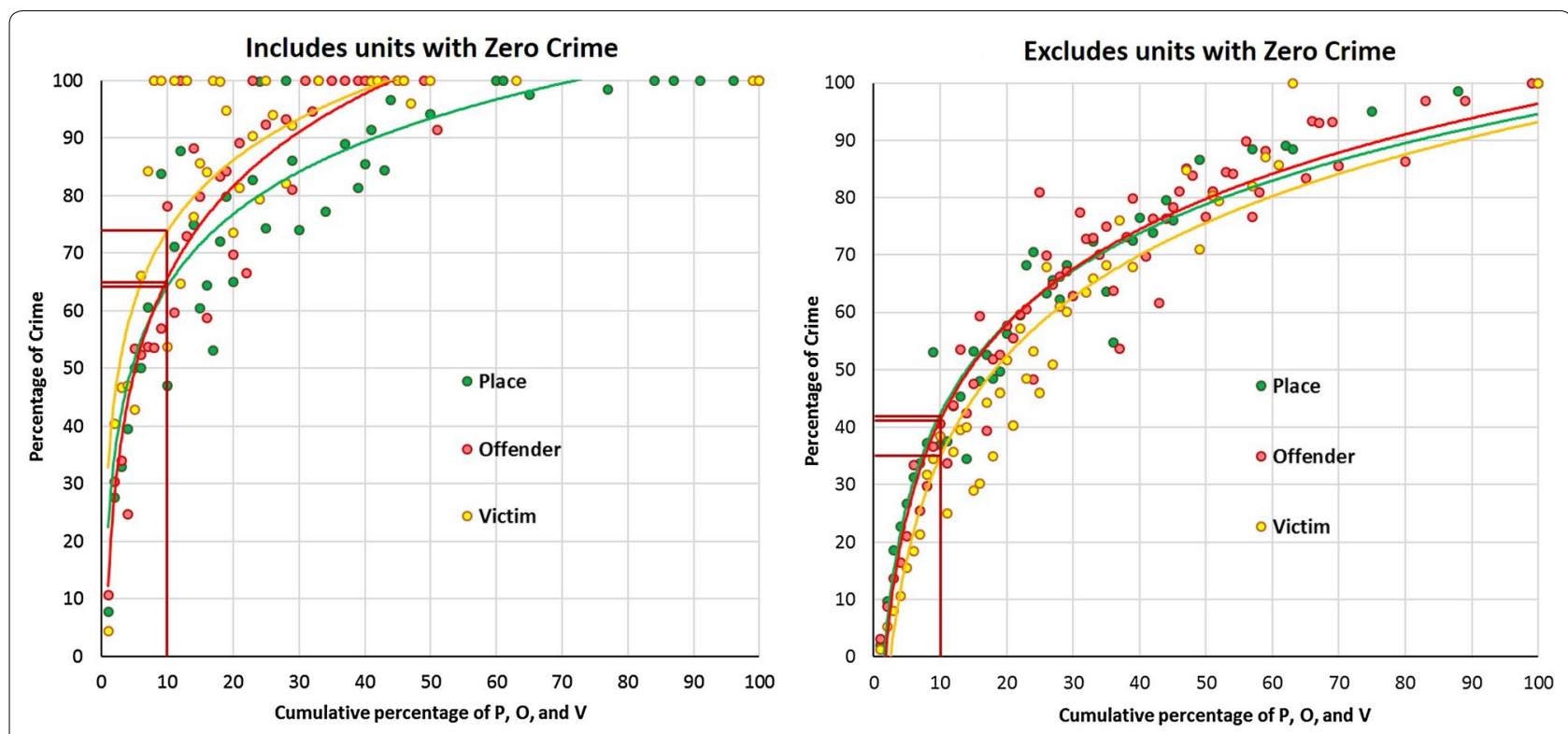

Fig. 4 Concentration of crime at places and among offenders and victims

(for details of the estimation process, see Lee, et al. 2017; Martinez et al. 2017; O et al. 2017). The Lorenz curves, above, were derived from these estimated functions. For all three units of analysis, there is more dispersion around the functions when we include places or people not involved in crime than when we exclude these cases (see Appendix A, Table 4, where the $\mathrm{R}^{2}$ statistics substantiate the visual impression of Fig. 4). We are uncertain why this might be the case. It implies that populations of places and people vary a great deal with regard to involvement in crime, but given involvement, the crime processes are relatively consistent across populations. We cannot rule out, however, that this is an artifact of the studies that were conducted and reported in the literature rather than something systematic in the nature of crime. It is certainly something that needs further investigation.

These curves are based on estimated coefficients, and an examination of the $95 \%$ confidence intervals around these coefficients shows that these confidence intervals overlap. These results suggest that we cannot rule out the possibility that the differences between the curves are due to chance (Appendix A shows the relevant significance tests). This suggests that the findings reported by Spelman and Eck (1989) - are not valid: crime at place is not more concentrated than crime among offenders and among victims. Or, more conservatively, we have no good evidence that crime is more concentrated at places than among offenders or victims. It also illustrates why it is important to synthesize evidence from numerous studies, and to update such reviews periodically.

\section{Victimization surveys and police data}

Another important comparison is between studies of crime concentration at addresses using reported crime data from the police and studies using victimization surveys of crimes at places. The second group includes 
crimes not reported to the police. Many victimization surveys report on place-based crime events (e.g., residential burglary and victimizations at commercial establishments). This comparison, therefore, is important for two reasons. It tells us whether measures of place crime concentration are sensitive to non-reporting of crime, and it tells us if victimization survey research can inform crime place theory and practice.

Figure 5 displays the concentration of crime at places as measured using these two types of data. It is easy to see that the two pairs of curves are very similar, though the logarithmic curves fit the police data better than the survey data (Appendix A, Table 5 provides information showing that there are no statistically significant differences between survey and reported crime concentration at places, whether or not crime non-involved places are examined). Table 3 shows the number of studies and data points used to estimate these curves, and compares the estimated Gini coefficients. From the figure and table, it is reasonable to conclude that much of the repeat victimization findings can be interpreted as findings about places, and that the absence of unreported crime in police data does not influence measures of concentration of crime at places.

\section{Relative concentration of crime at micro-levels of analysis}

Based on the evidence to date, it appears that crime is about equally concentrated at places, among offenders and among victims. If there are differences, the differences are probably not great. Conservatively, one can assert that the similarity in concentration is greater than the differences. Three implications flow from these findings.
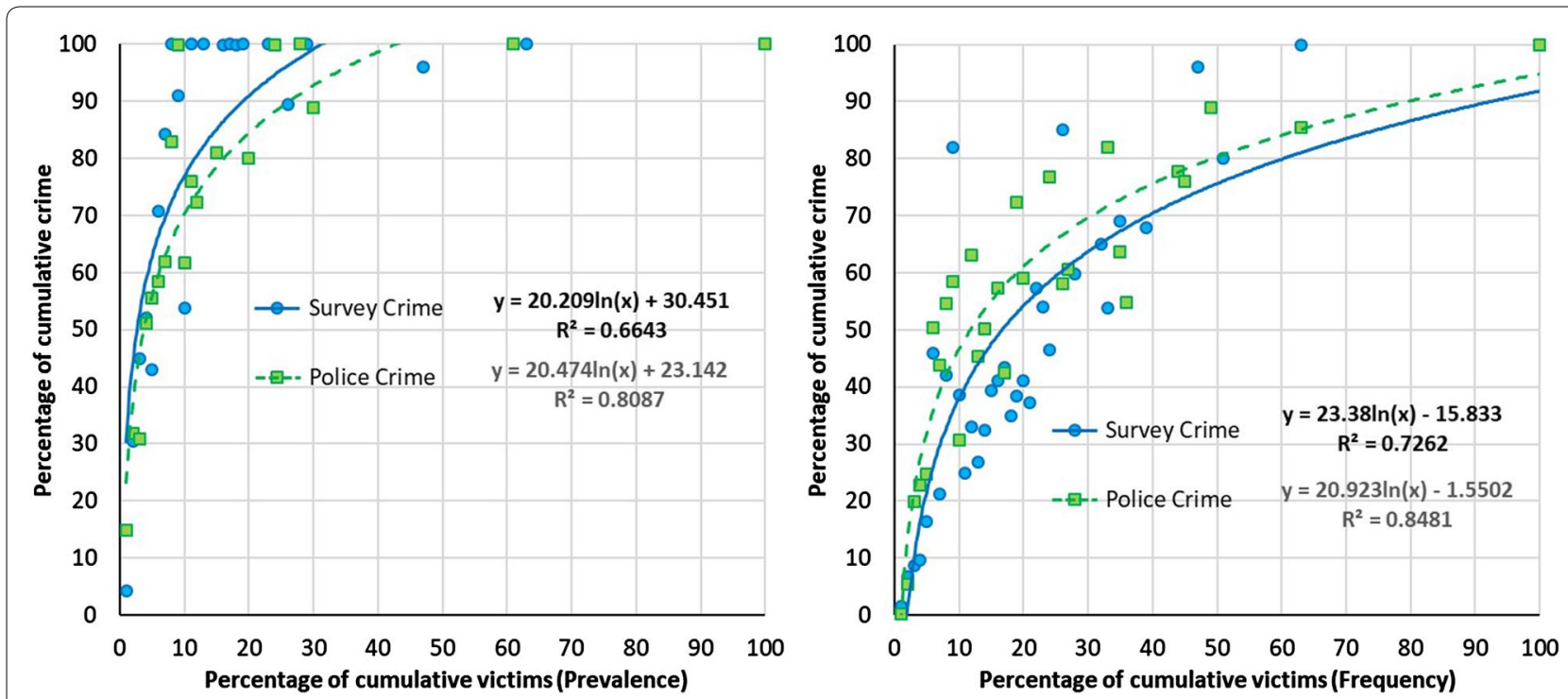

Fig. 5 POV victimization (survey) data vs. police reported data

Table 3 Comparison of Gini coefficients for studies using police data and those using survey data

\begin{tabular}{|c|c|c|c|c|c|c|}
\hline \multirow[b]{2}{*}{ Studies using... } & \multicolumn{3}{|c|}{ Including non-crime cases } & \multicolumn{3}{|c|}{ Excluding non-crime cases } \\
\hline & Studies reviewed & Data points analyzed & Gini & Studies reviewed & Data points analyzed & Gini \\
\hline Police data of reported crime ${ }^{a}$ & 5 & 83 & .83 & 7 & 83 & .47 \\
\hline Victimization survey data ${ }^{\mathrm{b}}$ & 12 & 196 & .87 & 12 & 186 & .33 \\
\hline Absolute difference in Gini coefficients & & & .04 & & & .14 \\
\hline
\end{tabular}

Data points are ordered pairs of numbers, where the first number is a percent of the places or people studied and the second number is the percent of crime involved with these places or people. For example, 15,70 would indicate that $15 \%$ of the places examined had $70 \%$ of the crime found in the study, or that $15 \%$ of the people surveyed had $70 \%$ of the victimizations detected in the study. This is described in Lee et al. (2017) and in O et al. (2017)

${ }^{\text {a }}$ For sources and methods, Lee et al. (2017)

${ }^{b}$ For sources and methods, $O$ et al. (2017) 
First, the similarity of concentration for places, offenders, and victims calls for an explanation. We can think of three. (A) The similarities are coincidental and nonsubstantive. They are chance occurrences that will disappear as more studies of concentration are produced. (B) The similarities are because the same offenders attack the same victims at the same places. If we have studies of places, offenders, and victims in the same area, we would find the most involved people and places are frequently in contact. (C) The same feedback mechanisms drive concentration among places, offenders, and victims, although their overlap (predicted in B) is minor. The existence of such a mysterious common process may seem outlandish, but in the next section we will show how common concentration is in human and natural affairs. Regardless of the explanation, much can be learned from reducing specialization: place researchers should try to account for offender and victims; offender researchers should try to account for places and victims; and victim researchers should try to account for offenders and places.

Second, our findings support Clarke and Cornish (2000) and Farrell et al. (1995): when looking at all places or people there may be different explanations for initial involvement in crime than repeated involvement, given the first crime.

Third, for prevention, developing interventions that take into account places, offenders, and victims seem more appropriate than using highly specialized strategies (place, or offender, or victim only). For policy purposes, selecting whether one should focus on places, offenders, or victims should not hinge on which is most concentrated in general. Rather, other considerations should be examined: availability of valid data describing who is most involved in crime and the availability of evidencebased interventions.

\section{Compared to non-crime phenomena}

There have been no systematic comparisons between crime-related phenomena and non-crime phenomena, though crime and place researchers have noted the apparent similarity among crime events and other phenomena (Sherman 2007; Weisburd 2015). So in this section we make an attempt to put crime concentration in the context of other forms of concentration noted in the scientific literature.

The commonness of concentration raises an important question: is concentration of crime at places (or among offenders or victims) substantially different from concentration in other fields of study? Income inequality, for example, has received considerable attention. Among industrialized countries, Iceland has the least (Gini of .244) and Chile has the greatest (Gini of .465) (Centre for Opportunity and Equality 2016). As we just saw, crime concentration is substantially greater. Are crime scientists dealing with a singular phenomenon, or are they investigating something that is merely an example of a general set of processes found throughout nature?

To see why comparing crime concentration to concentration in other fields is important, consider three alternative possibilities. First, consider the possibility that crime is substantially more concentrated at places than other phenomena are concentrated. This would suggest that there is something very special about the processes by which crime concentrates, and that those who study crime must develop explanations different from explanations describing concentration in other fields.

Second, consider the possibility that crime concentrates at places substantially less than other phenomena concentrate. If this possibility is true, then there are substantial constraints on crime or places that prevent crime from behaving like other phenomena. Or, that the processes concentrating crime are different and weaker than the processes concentrating other phenomena. And like the first possibility, it suggests crime scientists are on their own: they cannot draw extensive insight from other fields.

Third, there is the possibility that crime is about as concentrated at places as other phenomena are concentrated. If this is true, then crime concentration at places (and among offenders and victims) is much like other phenomena in nature, that the processes that lead to concentration are similar across domains, and that crime scientists would be advised to draw on lessons from fields far removed from crime. Further, policy makers may be able to take general lessons from policies to address other problems where concentration is important (e.g., use of medical facilities), even if these problems have no obvious connection to crime.

Conducting a systematic review of non-crime phenomena is extremely difficult, and we will not attempt it here. The reasons for this difficulty are obvious. First, the phenomena span from physics, computer science, chemistry, and biology to psychology, economics, sociology, political science, and literature. Within each of these broad fields are numerous subfields where concentration might be found. Thus, a systematic review would have to incorporate all of science. Second, the terminology varies a great deal among the various disciplines. This makes it difficult to create search terms. Third, the way the data is portrayed varies considerably: from tables to formulas. Thus, comparing across available studies is difficult.

One alternative is to conduct a standard review and assess those studies that are prominent in the literature. The difficulty here is that this could create biases toward 


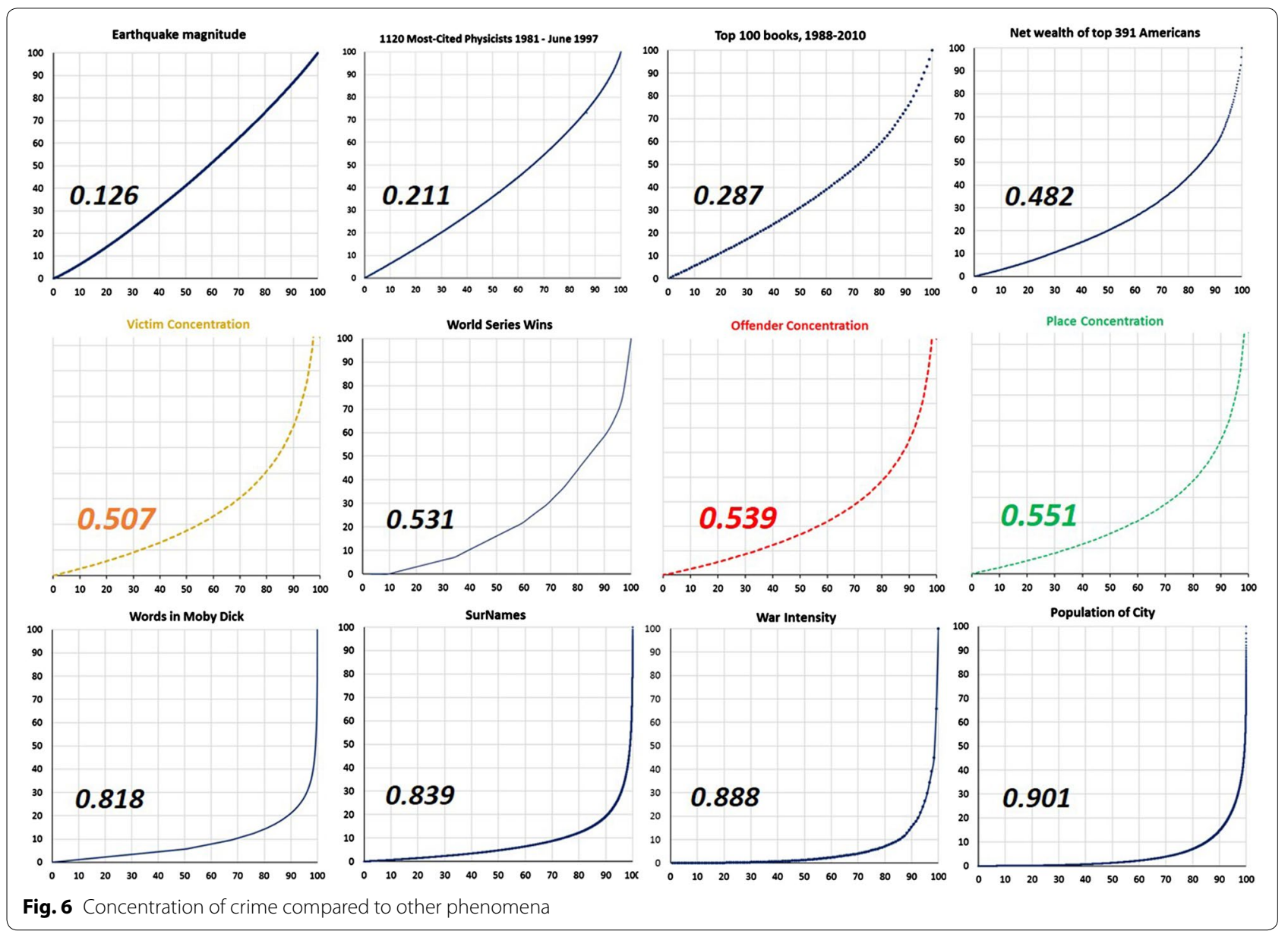

conclusions favorable to the authors' (our) preconceived notions.

To be both pragmatic and objective, we relied on Newman's (2005) review. Newman, writing in a physics journal, is not interested in crime, and selected his examples with something else in mind. This could be a biased sample of the unknown population of studies that could be reviewed, but it is highly unlikely to be biased in a way that distorts a comparison to crime. Further, Newman standardizes the way he describes the distributions, thus making comparisons to crime feasible.

Drawing on examples used by Newman (2005) we sought out the data sets he used, or a more recent version of such data. The phenomena we examined are mostly human activity related, though we include earth quakes as a useful reference. We also compare these other phenomena to places, offenders, and victims with some involvement in crime. This is because almost all of these other phenomena have no definable "uninvolved" case (e.g., there can be no earthquake without some energy release, and the word frequency in Moby Dick does not show words not in this masterpiece).
Figure 6 displays twelve charts of different phenomena plotted to show a Lorenz curve with its Gini score. They are in increasing order of concentration. Earthquakes show the concentration of energy released by each event. ${ }^{8}$ The second graph shows citations of top physicists. ${ }^{9}$ Next we show sales of the 100 best-selling books. ${ }^{10}$ This is followed by a chart showing the concentration of wealth among the richest Americans. ${ }^{11}$ Some baseball teams

\footnotetext{
${ }^{8}$ The data for this chart come from the U.S. Earthquake Intensity Database. It shows a magnitude of 23,000 U.S. earthquakes for each recorded earthquake event (https://www.ngdc.noaa.gov/nndc/struts/ form $? \mathrm{t}=101650 \& \mathrm{~s}=35 \& \mathrm{~d}=35$ ).

9 This data covers all publications from ISI catalogued journals from January 1981 to June 1997 and was compiled by Small and Pendlebury of the Institute for Scientific Information. (http://physics.bu.edu/ redner/projects/citation/physics-by-person.html). It shows the number of citations from ISI catalogued journals for each of the most cited physicists.

10 This chart illustrates that a few of the 100 top selling books from the 50th week of 1998 to the week ending on December 11, 2010 that had most of the sales. These data come from The Guardian (https://www.theguardian. com/news/datablog/2011/jan/01/top-100-books-of-all-time).

${ }^{11}$ Wealth is concentrated, even among the wealthiest. The data for this chart come from Forbes.com (http://www.forbes.com/lists/2010/10/billionaires-2010_The-Worlds-Billionaires_Networth.html).
} 
have won more world series championships than others, and this is show in the fifth chart. ${ }^{12}$ Place and offender crime (Lee et al. 2017; Martinez et al. 2017) are more concentrated. Since Zipf (1949), we have known that word use is concentrated. In the eighth graph we show this using Moby Dick. ${ }^{13}$ Surnames are also concentrated-more people in the U.S. have Smith as a last name than people who have the last name of Dromgoole. ${ }^{14}$ Crime victimization is more concentrated than surnames ( $\mathrm{O}$ et al. 2017). War intensity-measured by the number of casualties - is even more concentrated-a few wars had most of the battle deaths. ${ }^{15}$ Finally, city size is the most highly concentrated: most people live in a few cities. $^{16}$

We can now put the concentration of crime at places, among victims, and among offenders in context. The examples we used are not necessarily representative of concentrations, so we cannot be certain where they rank with regard to concentration. We are probably on safe footing, however, if we note that crime's concentration is well within the range of phenomena documented. It is neither at the bottom nor at the top. And with regard to the concentration of crime at places, there is nothing here to show that it is exceptional.

There are theory and research implications from these findings. Most obviously, the concentration of crime at places (and among offenders and victims) is not an anomaly. It is neither far more nor far less concentrated than other phenomena. In this context, crime is typical with regard to concentration. If criminologists had payed attention to concentration evidence

\footnotetext{
${ }^{12}$ Some professional baseball teams never won a world series, while a few have won numerous championships. These data, showing team performance from 1901 to 2016 come from Baseball-reference.com (http://www. baseball-reference.com/leagues/MLB/).

13 To develop this chart, we count all words used in the Moby Dick, from the most frequent word (i.e., the) to the least frequent word (i.e., aback). There are over 1 million words in the English language (1,025,109.8 according to the Global Language Monitor) http://www.languagemonitor.com/ number-of-words/number-of-words-in-the-english-language-1008879/. Accessed July 15, 2016).

14 This chart's data come from the 2000 U.S. census bureau and shows the number of individuals with each last name occurring 100 or more times in the 2000 Census data (http://www.census.gov/topics/population/genealogy/data/2000_surnames.html). The most frequent last name was 'Smith' (appears 2376,206 times).

15 Wars vary in size, and size can be measured in a number of ways (combatants, casualties, and so forth). The data for this chart comes from Small and Singer (1982) and measures intensity by battle deaths. By definition, there cannot be any zero-intensity wars.

16 The data for this chart comes from the U.S. Census Bureau webpage providing resident population estimates from April 1, 2010 to July 1, 2015 (https://www.census.gov/popest/data/cities/totals/2015/SUB-EST2015. $\mathrm{html}$ ). To be a city, an area must have some population, so there cannot be any zero-population cities. Like the war intensity concentration, this illustrates high concentration without zero-events.
}

throughout the natural and social sciences, they would have expected crime concentration. Because there does not appear to be anything peculiar about crime's concentration, it is likely that processes that give rise to concentration in physics, geology, biology, economics, medicine, computer sciences, and other disciplines have analogs in the study of crime. Researchers and theorists should adapt these processes to explaining crime. Some may not be applicable, but some will. More generally, those who study crime should avoid talking of their field as a singular discipline and think of it as a multidisciplinary endeavor. Practically, when recruiting new faculty, for example, university departments that specialize in the study of crime should draw broadly from candidates, and not give special preference to candidates with criminal justice, criminology, or sociological training-geographers, physicists, psychologists, computer scientists, political scientists, and economists, among others have much to offer.

From a policy perspective these findings do not have specific implications. But they do have important general implications. Policy makers concerned with crime may be able to learn a great deal from successful and failed policies addressing other problems that are concentrated. The medical field, for example, suffers from a concentration of users: a few patients consume most of the medical resources (Jacobi 2012). Those charged with regulating economic activity also face problems created by monopolies and oligopolies: the concentration of commerce in a single or few firms (Rhoades 1993). There may be lessons here as well.

\section{Conclusions}

In this paper we set out to establish a context for interpreting the concentration of crime at places. We did this through three sets of comparisons: (1) crime concentration at places to crime concentration at larger geographic units, (2) place crime concentration compared to the concentration of crime among offenders and victims, and (3) place crime concentration compared to non-crime phenomena concentration. We have already provided conclusions at each step, so here we will summarize them.

1. The smaller the geographical unit the greater the concentration. Much of this added concentration is due to the absence of crime in most of the smallest units (addresses and segments).

2. When researchers examine only geographic units with at least one crime the evidence suggests that are few substantive differences in concentration.

3. When we examine both crime uninvolved and involved cases, crime maybe about equally concentrated among places, offenders and victims. This con- 
tradicts the findings of Spelman and Eck (1989) who suggested crime is more concentrated at places and least concentrated among victims.

4. When we only examine crime involved cases, the amount of crime concentration across these three domains is also very similar. This too contradicts the findings of Spelman and Eck (1989).

5. Among natural and social phenomena demonstrating concentration, crime does not stand out as being particularly concentrated-some phenomena are more and some are less concentrated than crime.

Whether one should examine all cases-crime-involved as well as uninvolved-when studying crime concentration depends on the question being asked. There is no a priori reason to prefer one way of looking at crime over the other. If one is interested in identifying where or among whom crime is most likely to occur, then looking at all places and people makes sense. If one is interested in understanding repeated involvement, then focusing on the crime-involved makes more sense.

Understanding the processes by which places become repeated locations for crimes is important. However, our reviews suggest that there is nothing peculiar about places with regard to this question: crime is just as concentrated among crime-involved places as it is among other crime-involved geographic units, among other key elements of crime, and in comparison to other social, biological, and physical phenomena.

In short, the choice of places over offenders and victims cannot be based on the idea that crime is more concentrated at places. A researcher might have a personal interest in places, just as researchers have personal interests in the study of victims or offenders. However, we cannot confuse this personal point of view with superior substantive importance. As places, offenders, and victims must interact to create crime, we should view the study of places to be just another perspective to understand and prevent crime.

Nonetheless, small geographic units may be far more important than larger ones. When we examine crimeinvolved and uninvolved places, there is a substantial and systematic decline in concentration from small units to larger ones. This suggests that the smallest units are at the core of the problem, but that larger units provide important contextual understanding (Wilcox et al. 2002). This role of the larger units disappears once we examine only those places with at least one crime (i.e., ignore places with no crime). Here it appears that crime concentration is not dependent on the geographic scale. These two conclusions suggest that larger geographic units might provide context useful for understanding initial crime involvement, but that they may be less important for understanding repeated crimes. The similarity in concentration among involved places, offenders, and victims suggests that it is the dynamics of the interactions of these micro-elements that drives much crime concentration at all geographic levels.

Finally, we should consider crime concentration to be a subset of the larger phenomena of concentration in the natural and social worlds. There is no evident reason to treat crime as something special or unique. Crime is concentrated, but so are many-if not most-things in the world. Given the ubiquity of concentration in natural and human affairs, and given the fact that many scientists in many disciplines study concentration, crime scientists may have more to learn from those who study non-crime phenomena than from those who study crime.

Given that concentration among natural and social phenomena is extremely common, we should assume that crime and any related phenomena are concentrated until we have data demonstrating this assumption is false. In short, when confronted with some new crime or act of deviancy, even before we have data, our default assumption should be that it is concentrated. Further, data that seem to indicate an absence of concentration should be treated with suspicion until it has been demonstrated that these data are not biased in some way. Finally, all crime reduction policies should be based on the concentration assumption, unless there are valid data to suggest otherwise.

\section{Authors' contributions}

This paper was conducted by a team. JEE headed the team and was the lead writer for this paper. YL provided expertise on place research and conducted much of the analysis. SO and NM provided expertise on offenders and victims (respectively) and editorial reviews.

\section{Author details}

${ }^{1}$ School of Criminal Justice, University of Cincinnati, Cincinnati, Ohio, USA.

${ }^{2}$ Department of Public Affairs, University of Colorado-Colorado Springs, Colorado, USA.

\section{Acknowledgements}

Special thanks to Bill Spelman, who saw the need for such comparisons over 25 years ago. Many thanks to David Weisburd, for his friendship and insights. And thanks to the two reviewers who asked great questions (some of which we could not answer). Finally, thank you Gloria and Rob for your patience.

\section{Competing interests}

The authors declare that they have no competing interests.

\section{Availability of data and materials}

Articles used in the systematic review are noted in the references. For other information regarding data, please contact the lead author.

\section{Ethics approval and consent to participate}

Does not apply. As a review of summary data from previously conducted research, no humans (or their tissues) participated as subjects in this research. 


\section{Appendix A}

The first part of this appendix shows the evidence that the sets of curves shown in Fig. 4 are not statistically different from each other. The second part leads to the same conclusion for the curves in Fig. 5.

The rows for Table 4 show the estimated coefficient for $\log$ of the bins for proportion of units $[\ln (\operatorname{bin} X)]$ along with its standard error and the lower and upper bounds of the 95\% confidence interval around the coefficient. It also shows the $\mathrm{p}$ value. Similar information is provided for the intercept. Finally, we show the R-square value for the logarithmic regression.

The first set of three columns shows the estimates for curves where all cases, whether crime-involved or not, are included. The second set of three columns shows the estimates for curves when only crime involved places, offenders and victims are analyzed.
Looking at the first set of columns is clear that the coefficients and intercepts are all significantly different from zero, using 95\% confidence intervals. With regard to the betas for $\ln ($ bin $X)$, their confidence intervals overlap substantially for places, offenders, and victims. Thus, we cannot claim that the three coefficients are different. The same is true of the intercepts' confidence intervals.

Looking at the second set of three columns, we come to the same conclusions based on the same criteria.

Based on the information in Table 5 we cannot reject the possibility that crime is equally concentrated regardless of the source of the crime data (victimization surveys or crimes reported to the police).

The rows in Table 5 are the same as the rows in Table 4. The first two columns compare studies using victimization surveys to studies using police reports for all places,

Table 4 Place vs. offender vs. victim concentration: logarithmic regression results

\begin{tabular}{|c|c|c|c|c|c|c|}
\hline & \multicolumn{3}{|c|}{ Crime uninvolved and involved } & \multicolumn{3}{|c|}{ Crime involved only } \\
\hline & Places & Offenders & Victims & Places & Offenders & Victims \\
\hline Beta $\ln ($ bin $X)$ & 18.13 & 23.17 & 17.78 & 22.67 & 23.91 & 25.35 \\
\hline SE beta & 1.75 & 1.67 & 2.11 & 1.05 & 0.87 & 1.35 \\
\hline Cl lower bound & 14.64 & 19.83 & 13.55 & 20.58 & 22.18 & 22.65 \\
\hline Cl upper bound & 21.63 & 26.52 & 22.01 & 24.77 & 25.65 & 28.04 \\
\hline $\mathrm{p}$ & $<0.01$ & $<0.01$ & $<0.01$ & $<0.01$ & $<0.01$ & $<0.01$ \\
\hline Intercept & 22.48 & 12.24 & 32.89 & -9.85 & -13.76 & -23.53 \\
\hline SE intercept & 5.64 & 5.03 & 6.46 & 3.27 & 2.96 & 4.20 \\
\hline Cl lower bound & 11.21 & 2.17 & 19.96 & -16.39 & -19.68 & -31.98 \\
\hline Cl upper bound & 33.76 & 22.31 & 45.81 & -3.32 & -7.84 & -15.14 \\
\hline $\mathrm{p}$ & $<0.01$ & 0.02 & $<0.01$ & $<0.01$ & $<0.01$ & $<0.01$ \\
\hline$R^{2}$ & 0.72 & 0.84 & 0.66 & 0.92 & 0.92 & 0.89 \\
\hline
\end{tabular}

Table 5 Survey crime vs. reported crime concentration: logarithmic regression results

\begin{tabular}{|c|c|c|c|c|}
\hline & \multicolumn{2}{|c|}{ Crime uninvolved and involved } & \multicolumn{2}{|c|}{ Crime involved only } \\
\hline & Survey events & Reported events & Survey events & Reported events \\
\hline Beta $\ln (\operatorname{bin} X)$ & 20.21 & 20.47 & 23.38 & 20.92 \\
\hline SE beta & 3.06 & 2.42 & 2.50 & 1.74 \\
\hline Cl lower bound & 14.08 & 15.64 & 18.38 & 17.45 \\
\hline Cl upper bound & 26.33 & 25.30 & 25.30 & 24.40 \\
\hline $\mathrm{p}$ & $<0.01$ & $<0.01$ & $<0.01$ & $<0.01$ \\
\hline Intercept & 30.45 & 23.14 & -15.83 & -1.55 \\
\hline SE intercept & 8.47 & 6.24 & 7.32 & 5.00 \\
\hline Cl lower bound & 13.51 & 10.67 & -30.48 & -11.55 \\
\hline Cl upper bound & 47.40 & 35.62 & -1.19 & 8.45 \\
\hline$p$ & $<0.01$ & $<0.01$ & 0.04 & 0.76 \\
\hline $\mathrm{R}^{2}$ & 0.66 & 0.81 & 0.73 & 0.85 \\
\hline
\end{tabular}


whether or not the place was involved with crime. Because some of the studies that used police reports also used calls for service, we decided to label these columns as "events" - a term that encompasses crimes but also includes other incidents reported to the police. The second pair of columns makes the same comparison, but only for places with at least one event.

For both pairs, the 95\% confidence intervals around the coefficients (or intercepts) overlap substantially. Consequently, we cannot claim crime concentration varies by data source.

\section{Publisher's Note}

Springer Nature remains neutral with regard to jurisdictional claims in published maps and institutional affiliations.

Received: 17 February 2017 Accepted: 10 July 2017

Published online: 17 July 2017

\section{References}

Andresen, M. A., \& Malleson, N. (2010). Testing the stability of crime patterns: Implications for theory and policy. Journal of Research in Crime and Delinquency, 48(1), 58-82.

Bak, P. (1994). Self-organizing criticality: A holistic view of nature. In G. Cowans, D. Pines, \& D. Meltzer (Eds.), Complexity: Metaphors, models, and reality (pp. 477-496). Boston: Addison-Wesley.

Bak, P. (1996). How nature works. New York: Copernicus.

Bartlett, J., Norrie, R., Patel, S., Rumpel, R., \& Wimberley, S. (2014). Misogyny on twitter. London: Demos.

Beckett, L. (2016). Gun inequality: US study charts rise of hardcore super owners. The Guardian. U.S. edition. September 19. https://www.theguardian. com/us-news/2016/sep/19/us-gun-ownership-survey. Accessed 12 December 2016.

Caputo, A., Gorner, J. (2016). Small group of cops repeatedly cost Chicago millions. Chicago Tribune. January 30. http://www.chicagotribune.com/ news/ct-chicago-police-misconduct-settlements-met-20160129-story. html. Accessed 30 January 2016.

Centre for Opportunity and Equality. (2016). Income inequality remains high in the face of weak recovery. Paris: The Organisation for Economic Cooperation and Development (OECD). November. http://www.oecd.org/ social/OECD2016-Income-Inequality-Update.pdf. Accessed 11 December 2016

Charbonneau, D., \& Dornhaus, A. (2015). Workers'specialized' on inactivity: behavioral consistency of inactive workers and their role in task allocation. Behavioral Ecology and Sociobiology, 69(9), 1459-1472.

Clarke, R. V. \& Cornish, D. B. (2000). Rational choice. In R. Paternoster \& R. Bachman (Eds.), Explaining crime and criminals: Essays in contemporary criminological theory (pp. 23-42). Los Angeles: Roxbury.

Clauset, A., Young, M., \& Gleditsch, K. S. (2007). On the frequency of severe terrorist events. Journal of Conflict Resolution, 51(1), 58-87.

Cohen, L. E., \& Felson, M. (1979). Social change and crime rate trends: a routine activity approach. American Sociological Review, 44(4), 588-608.

Eck, J. E. (2001). Policing and crime event concentration. In R. F. Meier, L. W. Kennedy, \& V. F. Sacco (Eds.), The process and structure of crime: Criminal events and crime analysis (pp. 249-276). New Brunswick: Transaction.

Farrell, G. (2015). Crime concentration theory. Crime prevention and community Safety, 17(4), 233-248

Farrell, G., Phillips, C., \& Pease, K. (1995). Like taking candy: Why does repeat victimization occur? British Journal of Criminology, 35(3), 384-399.

Fauset, S., Johnson, M. O., Gloor, M., Baker, T. R., Monteagudo, M. A., Brienen, R. J. W., et al. (2015). Hyperdominance in Amazonian forest carbon cycling. Nature Communications, 6, 6857-6866.

Felson, M. (1995). Those who discourage crime. In J. E. Eck \& D. Weisburd (Eds.), Crime and place (pp. 53-66). Monsey: Criminal Justice Press.
Forst, B., Leahy, F. J., Jr., Shirhall, J., Tyson, H. L., \& Bartolomeo, J. (1982). Arrest convictability as a measure of police performance. Washington, DC: INSLAW.

Gabaix, X. (1999). Zipf's law for cities: An explanation. The Quarterly Journal of Economics, 114(3), 739-776.

Gisiger, T. (2001). Scale invariance in biology: Coincidence or footprint of a universal mechanism? Biological Reviews, 76(2), 161-209.

Ijiri, Y., \& Simon, H. A. (2013). Interpretations of departures from the Pareto curve firm-size distributions. Journal of Political Economy, 82(2), 315-331.

Jacobi, J. V. (2012). High utilizers of ED services: Lessons for system reform. Annals of Health Law, 21(1), 35-44.

Johnson, S. D. (2010). A brief history of the analysis of crime concentration. European Journal of Applied Mathematics., 21(4-5), 349-370.

Laherrère, J., \& Sornette, D. (1998). Stretched exponential distributions in nature and economy: "Fat tails" with characteristic scales. The European Physical Journal B, 2(4), 525-539.

Lee, Y., Eck, J. E., SooHyun, O., \& Martinez, N. N. (2017). How concentrated is crime at places? A systematic review from 1970 to 2015. Crime Science. doi:10.1186/s40163-017-0069-x.

Lorenz, M. O. (1905). Methods of measuring the concentration of wealth. Publications of the American Statistical Association, 9(70), 209-219.

Madensen, T. D., \& Eck, J. E. (2013). Crime places and place management. In F. T. Cullen \& P. Wilcox (Eds.), Oxford Handbook of Criminological Theory (pp. 554-578). New York: Oxford University Press.

Martinez, N. N., Lee, Y., Eck, J. E., \& O, S. (2017). Ravenous wolves revisited: A systematic review of offending concentration. Crime Science (forthcoming).

Mathis, J., Rumpl, W., \& Nordsieck, K. H. (1977). The size distribution of interstellar grains. The Astrophysical Journal, 217, 425-433.

McElligott, A. G., \& Hayden, T. J. (2000). Lifetime mating success, sexual selection and life history of fallow bucks (Dama dama). Behavioral Ecology and Sociobiology, 48(3), 203-210.

Newman, M. E. J. (2005). Power laws, Pareto distributions and Zipf's law. Contemporary Physics, 46, 323-351.

Noorden, RV., Maher, B. \& Nuzzo, R. (2014). The top 100 papers: Nature explores the most-cited research of all time. Nature. http://www.nature. com/news/the-top-100-papers-1.16224.

O, S., Martinez, N., Lee, Y., \& Eck, J. E. (2017). How concentrated is crime among victims? A systematic review from 1977 to 2014. Crime Science (under review).

Pierce, G., Spaar, S., \& Briggs, L. R. (1988). The character of police work: Strategic and tactical implications. Boston: Center for Applied Social Research, Northeastern University.

Piketty, T., \& Saez, E. (2003). Income inequality in the United States, 1913-1998. The Quarterly Journal of Economics, 118(1), 1-41.

Rengert, G., Mattson, M., \& Henderson, K. (2001). Campus Security: Situational Crime Prevention in High-Density Environments. Monsey: Criminal Justice Press.

Rhoades, S. A. (1993). The Herfindahl-Herschman index. Federal Reserve Bulletin, 79(3), 188-189.

Richardson, L. F. (1948). Variation of the frequency of fatal quarrels with magnitude. Journal of the American Statistical Association, 43(244), 523-546.

Richter, C. F. (1935). An instrumental earthquake magnitude scale. Bulletin of the Seismological Society of America, 25(1), 1-32.

Schmeiser, S. (2015). The size distribution of websites. Economics Letters, 128, 62-68.

Schneider, J., Madsen, T. \& Boggs, J. (2013). America's dirtiest power plants: Their oversized contribution to global warming and what we can do about it. Boston: Environment America Research and Policy Center.

Schroeder, M. (1991). Fractals, chaos, power laws: minutes from an infinite paradise. New York: Freeman.

Shaw, C. R., \& McKay, H. D. (1942). Juvenile delinquency and urban areas. Chicago: University of Chicago Press.

Sherman, L. W. (2007). The power few hypothesis: Experimental criminology and the reduction of harm. Journal of Experimental Criminology, 3(4), 299-321.

Sherman, Lawrence W., Gartin, P. R., \& Buerger, M. E. (1989). Hot spots of predatory crime: Routine activities and the criminology of place. Criminology, $27(1), 27-55$.

Small, M., \& Singer, J. D. (1982). Resort to arms: international and civil war 1816-1980. Beverly Hills: Sage.

Spelman, W., \& Eck, J. E. (1989). Ducks wolves \& helping hands: New approaches to urban policing. Public Affairs Comment, 35(2), 1-9. 
Steenbeek, W., \& Weisburd, D. (2016). Where the action is in crime? An examination of variability of crime across different spatial units in The Hague, 2001-2009. Journal of Quantitative Criminology, 32(3), 449-469.

Visser, E., Pijl, Y. J., Stolk, R. P., Neeleman, J., \& Rosmalen, J. G. M. (2007). Accident proneness, does it exist? A review and meta-analysis. Accident Analysis and Prevention, 39(3), 556-564.

Weisburd, D. (2015). The law of crime concentration and the criminology of place. Criminology, 53(2), 133-157.

Weisburd, D., Bushway, S., Lum, C., \& Yang, S.-M. (2004). Trajectories of crime at places: A longitudinal study of street segments in the city of Seattle. Criminology, 42(2), 283-321.

Weisburd, D., Eck, J. E., Braga, A., Telep, C., Cave, B., Bowers, K., et al. (2016). Place matters: Criminology for the 21st century. New York: Cambridge University Press.
Wilcox, P., \& Eck, J. E. (2011). Criminology of the unpopular: Implications for policy aimed at payday lending facilities. Criminology \& Public Policy, 10(2), 473-482.

Wilcox, P., Land, K., \& Hunt, S. (2002). Criminal circumstance: A dynamic multicontextual criminal opportunity theory. New York: Routledge.

Wolfgang, M. E., Figlio, R., \& Sellin, T. (1972). Delinquency in a birth cohort. Chicago: University of Chicago Press.

Zipf, G. K. (1949). Human behavior and the principle of least effort. Cambridge: Addison-Wesley.

\section{Submit your manuscript to a SpringerOpen ${ }^{\circ}$} journal and benefit from:

- Convenient online submission

- Rigorous peer review

- Open access: articles freely available online

- High visibility within the field

- Retaining the copyright to your article

Submit your next manuscript at $\boldsymbol{\nabla}$ springeropen.com 